\title{
Editorial
}

\section{Tsunami Science and Engineering II}

\author{
Valentin Heller D \\ Environmental Fluid Mechanics and Geoprocesses Research Group, Faculty of Engineering, \\ University of Nottingham, Nottingham NG7 2RD, UK; Valentin.Heller@nottingham.ac.uk; \\ Tel.: +44(0)-115-748-6049
}

Received: 11 September 2019; Accepted: 11 September 2019; Published: 13 September 2019

Keywords: earthquake-tsunamis; landslide-generated impulse waves; landslide-tsunamis; long wave run-up; numerical modelling; physical modelling; seismic tsunamis; tsunami hazard assessment and mitigation; tsunami loading on structures

Earthquake-tsunamis, including the 2004 Indian Ocean Tsunami, with approximately 227,898 casualties, and the 2011 Tōhoku Tsunami in Japan, with 18,550 people missing or dead [1], serve as tragic reminders that such waves pose a major natural hazard to human beings. Landslide-tsunamis, including the 1958 Lituya Bay case, may exceed $150 \mathrm{~m}$ in height and similar waves generated in lakes and reservoirs may overtop dams and cause significant devastation downstream, such as in the 1963 Vajont case with nearly 2,000 casualties [1].

In January 2018, I was invited by the editorial office of the Journal of Marine Science and Engineering to act as guest editor of the special issue Tsunami Science and Engineering II to collect articles about tsunamis with the aim to repeat the success of the special issue Tsunami Science and Engineering [2]. I was very keen on this project aimed at representing a wide range of high-level contributions to capture the recent increase in research activity in the field of tsunamis due to a series of recent catastrophes such as the 2018 Java and Sumatra volcanic-eruption-triggered landslide-tsunami, the 2018 Sulawesi earthquake-triggered underwater landslide-tsunami, the 2017 Greenland landslide-tsunami, the 2015 Chile earthquake-tsunami and the 2011 Tōhoku earthquake-tsunami, amongst others [1].

This book includes nine excellent contributions [3-11] to this special issue published between 2018 and 2019. The overall aim of the collection is to improve modelling and mitigate the destruction of tsunamis and the negative effects they have on us and our environment. The articles cover a wide range of topics around tsunamis, and reflect scientific efforts and engineering approaches in this challenging and exciting research field.

The order of the nine articles [3-11] in this book follows the three tsunami phases: generation, propagation and their effects. The first article from Perez del Postigo et al. [3] focuses on tsunami generation and propagation. The large magnitude of some tsunamis has been justified with a dual-source mechanism, for example as a combination of an earthquake- with a landslide-tsunami. Perez del Postigo et al. [3] is one of the first study investigating such a dual-source mechanism. They developed a unique experimental set-up in a $20 \mathrm{~m}$ flume to reproduce a coupled-source tsunami generation by an underwater fault rupture followed by a submarine landslide. One of their key-findings is that for a coupled-source scenario, the generated wave is crest led, followed by a trough of smaller amplitude decreasing steadily as it propagates along the flume.

The following two articles from Tan et al. [4] and Tessema et al. [5] involve the entire process of subaerial landslide-tsunami generation, propagation and runup. This is challenging, both from a numerical (typically requiring several models) and physical modelling point of view given that multiple physical processes at different length and time scales need to be modelled. Tan et al. [4] present a numerical landslide-tsunami hazard assessment technique, illustrated with hypothetical scenarios at Es Vedrà, offshore Ibiza, involving the site-specific bathymetry and topography. The violent wave 
generation process is modelled with the meshless Lagrangian method smoothed particle hydrodynamics and the simulations are continued with the less computational expensive non-hydrostatic non-linear shallow water equations code SWASH. The up to $133 \mathrm{~m}$ high tsunamis decay relatively fast with distance from Es Vedrà to $14.2 \mathrm{~m}$ offshore Cala d'Hort ( $3 \mathrm{~km}$ from the source) with a maximum run-up height of around $21.5 \mathrm{~m}$. Nearly all numerical and physical model studies into landslide-tsunamis released the slide in the longitudinal direction of the flume or basin, which does not well represent slide impacts in narrow reservoirs in lateral direction. This shortage motivated Tessema et al. [5] to investigate landslides impacting a reservoir in lateral direction in a 1:190 laboratory scale model for a typical dam of $\approx 60 \mathrm{~m}$ in height. They derived new empirical equations for the dam overtopping volume in a function of the slide volume, slide release height, slide impact velocity, still-water depth and upstream dam face slope. They further compare the measured overtopping volumes with a two-dimensional (2D) case reported in the technical literature and highlight some discrepancies supporting the need for their new results.

The next two contributions from Kian et al. [6] and Santos et al. [7] focus on wave propagation and inundation. Frequency dispersion can be very important for tsunami propagation. Kian et al. [6] apply the tsunami model NAMI DANCE, based on the computational efficient nonlinear shallow-water equations, to a range of problems from the technical literature. They show that for certain conditions of grid size, time step and water depth, the model is well capable of capturing small physical dispersion. Kian et al. [6] conclude that their model represents an acceptable alternative to the more computational demanding nonlinear Boussinesq-type equations models if dispersion is small. Santos et al. [7] provide a very detailed record and reconstruction of the 1755 Lisbon earthquake, tsunami and fire in downtown Lisbon. To achieve this, they combine detailed analysis of historical data with tsunami modelling based on the TUNAMI-N2 code and a field survey. Santos et al. [7] found that the number of residences in downtown Lisbon decreased from 26,200 to $6000-8800$ due to this catastrophe, partially due to 1000 fatalities. Further, the buildings were mainly destroyed by fires rather than the earthquake, as was previously believed, followed by tsunami inundation of up to $200 \mathrm{~m}$ into seafront streets and squares.

Evers and Boes [8] focus on impulse wave (tsunami) runup based on an experimental dataset containing 359 runup heights from the technical literature. This extensive dataset is compared to a range of existing empirical and analytical runup equations. Based on this analysis, Evers and Boes [8] propose a superior semi-empirical prediction equation representing the dataset with an overall $\pm 20 \%$ scatter for a wide range of slope and wave conditions.

The last three articles from Istrati et al. [9] and Ghodoosipour et al. [10,11] investigate the impact of tsunamis on bridges and pipelines, respectively, motivated by recent tsunamis damaging and/or destroying such critical infrastructure. Istrati et al. [9] investigate tsunami impact on a bridge with open girders to decipher the tsunami overtopping process and the associated demand on the bridge and its structural components. They find that the maximum horizontal and vertical forces do not always occur simultaneously and that the application of these forces at the centre of gravity of the deck does not yield conservative estimates of the uplift demand in individual connections as offshore connections have to withstand the largest uplift among all connections. They propose "tsunami demand diagrams" as visual representations of the complex variation of the tsunami loading and demand a paradigm shift in the assessment of tsunami risk to coastal bridges to include the distribution of this load to individual structural components, rather than only the total tsunami loading.

Both Ghodoosipour et al. [10] and Ghodoosipour et al. [11] rely on the identical experiments with Ghodoosipour et al. [10] carefully introducing into the dam-break flow characteristics and the influence of the presence of pipelines on flow conditions for a wide range of Froude numbers. The experiments involved both dry and wet beds to assess the influence of different impoundment depths and still water levels on the hydrodynamic features. Ghodoosipour et al. [11] investigate the hydrodynamic forces and moments these tsunami-like bores [10] exert on pipes. Based on their results, Ghodoosipour et al. [11] found resistance coefficients in the range of 1.0 to 3.5 and lift coefficients in the range of 0.5 to 3.0, which are very valuable for the design of pipelines located in tsunami-prone areas. 
These brief summaries illustrate the wide range of relevant and fascinating topics covered in this book. I would like to thank all Authors for their excellent articles and for contributing to the success of Tsunami Science and Engineering II. I hope that these articles will help to mitigate the negative effects of tsunamis and inspire many future research activities in this important research field.

Valentin Heller: Guest Editor "Tsunami Science and Engineering II"

Conflicts of Interest: The author declares no conflict of interest.

\section{References}

1. Wikipedia. List of tsunamis. 2019. Available online: https://en.wikipedia.org/wiki/List_of_tsunamis (accessed on 10 September 2019).

2. Heller, V. (Ed.) Tsunami science and engineering. 2016. Available online: https://www.mdpi.com/books/ pdfview/book/209 (accessed on 10 September 2019).

3. Perez del Postigo, N.; Raby, A.; Whittaker, C.; Boulton, S.J. Parametric study of tsunamis generated by earthquakes and landslides. J. Mar. Sci. Eng. 2019, 7, 154. [CrossRef]

4. Tan, H.; Ruffini, G.; Heller, V.; Chen, S. A numerical landslide-tsunami hazard assessment technique applied on hypothetical scenarios at Es Vedrà, offshore Ibiza. J. Mar. Sci. Eng. 2018, 6, 111. [CrossRef]

5. Tessema, N.N.; Sigtryggsdóttir, F.G.; Lia, L.; Jabir, A.K. Case study of dam overtopping from waves generated by landslides impinging perpendicular to a reservoir's longitudinal axis. J. Mar. Sci. Eng. 2019, 7, 221. [CrossRef]

6. Kian, R.; Horrillo, J.; Zaytsev, A.; Yalciner, A.C. Capturing physical dispersion using a nonlinear shallow water model. J. Mar. Sci. Eng. 2018, 6, 84. [CrossRef]

7. Santos, A.; Correia, M.; Loureiro, C.; Fernandes, P.; da Costa, N.M. The historical reconstruction of the 1755 earthquake and tsunami in downtown Lisbon, Portugal. J. Mar. Sci. Eng. 2019, 7, 208. [CrossRef]

8. Evers, F.M.; Boes, R.M. Impulse wave runup on steep to vertical slopes. J. Mar. Sci. Eng. 2019, 7, 8. [CrossRef]

9. Istrati, D.; Buckle, I.; Lomonaco, P.; Yim, S. Deciphering the tsunami wave impact and associated connection forces in open-girder coastal bridges. J. Mar. Sci. Eng. 2018, 6, 148. [CrossRef]

10. Ghodoosipour, B.; Stolle, J.; Nistor, I.; Mohammadian, A.; Goseberg, N. Experimental study on extreme hydrodynamic loading on pipelines. Part 1: Flow hydrodynamics. J. Mar. Sci. Eng. 2019, 7, 251. [CrossRef]

11. Ghodoosipour, B.; Stolle, J.; Nistor, I.; Mohammadian, A.; Goseberg, N. Experimental study on extreme hydrodynamic loading on pipelines. Part 2: Induced force analysis. J. Mar. Sci. Eng. 2019, 7, 262. [CrossRef]

(C) 2019 by the author. Licensee MDPI, Basel, Switzerland. This article is an open access article distributed under the terms and conditions of the Creative Commons Attribution (CC BY) license (http://creativecommons.org/licenses/by/4.0/). 